ARTICLE HISTORY: Received: August: 6, 2021 Accepted: September 27, 2021 Published: October 4, 2021

\title{
МОДЕРНИЗАЦИЯ ЗДАНИЙ С ЦЕЛЬЮ ПОВЫШЕНИЯ ЭНЕРГОЭФФЕКТИВНОСТИ, КОМФОРТА И БЕЗОПАСНОСТИ ПРОЖИВАНИЯ, А ТАКЖЕ ПРОДЛЕНИЯ СРОКА ЭКСПЛУАТАЦИИ ЖИЛЫХ ЗДАНИЙ
}

\author{
Яхья Мохаммед Яхья Мохаммед \\ кандидат технических наук, \\ старший преподаватель кафедры архитектуры и градостроительства, \\ Белгородский государственный технологический университет им. В.Г. Шухова, \\ 2. Белгород \\ Доцент кафедры архитектуры, Курский государственный университет, \\ 2. Курск
}

\begin{abstract}
Аннотация. Разбирается формирование нынешних технологий проектирования. Рассмотрена нынешняя обстановка в предназначенной работы, плюсы а также минусы технологических процессов концепции автоматизированного проектирования (САПР). Исследованы способности проектирования вместе с использованием 3D САПР, дозволяющие правильно создавать планы, технологические процессы с целью совместной работы с фасетной геометрией. Сформулированы заключения касательно перспективности с точки зрения увеличения производительности применения САDприложения совместно со встроенными способностями, не только параметрическими, а также с точки зрения непосредственного прогнозирования.

Представлены сегодняшние технологические процессы проектирования: 3D-представление, фотографирование, а также лазоревое сканирование, производящее планирование, 3Dпечать.

Annotation. The formation of current design technologies is analyzed. The current situation in the intended work, the pros and cons of technological processes of the concept of computer-aided design (CAD) are considered. The ability to design together with the use of 3D CAD, allowing to correctly create plans, technological processes for the purpose of joint work with facet geometry, is investigated. Conclusions are formulated regarding the prospects from the point of view of increasing the productivity of the application of the $\mathrm{CD}$ application together with built-in abilities, not only parametric, but also from the point of view of direct forecasting.

Today's technological processes of design are presented: 3D-representation, photography, as well as azure scanning, making planning, 3D printing.

Ключевые слова: теплотехнические свойство, реконструкция жилищного фонда, энергоэффективности реконструируемых строений

Keywords: thermal properties, reconstruction of housing stock, energy efficiency of reconstructed buildings

Введение. Проблемы обеспечения жильем населения Российской Федерации, улучшения качества жилищных условий, формирования городской среды, наиболее полно отвечающей потребностям современного человека и общества, с 20-х годов прошлого века оставались всегда. существенный. В современной России он не потерял былой актуальности.

Для решения жилищного вопроса необходимо не только много и быстро строить, но и правильно эксплуатировать жилые дома, своевременно ремонтировать и реконструировать жилищный фонд и улучшать его благоустройство. Земельные ресурсы страны позволяют возводить новые здания и сооружения, но именно модернизация старого жилищного фонда является наиболее оптимальной мерой с экономической и экологической точек зрения.

Типовые пятиэтажки спроектированы и построены по стандартам полувека назад с использованием малоэффективных теплоизоляционных материалов, а тепловые характеристики их ограждений не соответствуют современным требованиям. Планировочные решения, внешний вид здания, эксплуатационные характеристики по тепло-, водо- и звукоизоляции не соответствуют современным нормативным требованиям и потребительским качествам.

Нарушение нормативных сроков периодичности капитального ремонта и реконструкции, нарушение теплотехнических нормативов привело к тому, что удельный расход топлива в жилищном секторе достиг 87-89 кг условного топлива на 1 кв. общая площадь в год, что в 3,5 раза больше, чем в Норвегии и Канаде с аналогичными климатическими условиями. И если $30 \%$ энергоресурсов связано с непроизводственными потерями в электроэнергетических, транспортных и распределительных установках, то оставшиеся 70\% потерь происходят непосредственно при потреблении в жилых домах. Поэтому при требуемой сегодня классификации энергоэффективности зданий по величине удельного расхода энергии на отопление необходимо учитывать основного потребителя тепловой энергии - упомянутый выше фонд пригодных для дальнейшей эксплуатации зданий, построенных ранее с минимально допустимым уровнем тепловой защиты.
\end{abstract}


Одноэтапная замена всех малоэффективных зданий на эффективные позволит сэкономить топливную энергию в жилых домах в размере 276 млн Гкал, что эквивалентно годовой экономии 52 млн тонн условного топлива, в том числе 24 млрд кубометров природного газ и 4 миллиона тонн нефти. Однако в России ежегодно сносится лишь 0,5\% жилых домов, а это значит, что на естественный вывод из эксплуатации неэффективного жилищного фонда уйдут столетия. Ситуацию можно изменить, приняв меры по утеплению зданий, которые при разумных затратах могут обеспечить экономию $35-60 \%$ от текущего уровня потребления. Отсутствие адекватных затрат на капитальный ремонт и недостаточное внимание к капитальному ремонту для экономии затрат на электроэнергию блокируют реализацию этого потенциала. Важно отметить, что не менее $60 \%$ воздействия на жилые дома можно получить по системам коллективного пользования и 40\% - за счет реализации мероприятий в квартирах.

В настоящее время разрабатывается комплексная программа масштабной реконструкции таких зданий, которая решает следующие задачи: утепление внешних стен (что снизит затраты на отопление), обновление столярных изделий, полную замену сетей и теплового оборудования, установка различных расходомеров и счетчиков во всем доме, укрепление или восстановление балконов и навесов, установка лифтов и теплых тамбуров в некоторых домах и т. д.

В связи с этим в последнее время проводятся исследования по повышению энергоэффективности реновируемых зданий за счет устранения «мостов холода», установки навесных и вентилируемых фасадов, дополнительных штукатурок и т.д. как отечественных ученых [10, 11, 12], так и зарубежных [13, 14, 15, 16]. Особый интерес представляет реконструкция «пассивных домов», широко используемых в Восточной Германии и Норвегии. [17, 18, 19].

Учитывая, что в настоящее время на российском рынке жилья преобладают здания со сроком эксплуатации более 30 лет, а объем нового строительства значительно уступает объемам ветхого и аварийного жилищного фонда, возникают вопросы реконструкции и восстановления жилого фонда. Здания и сооружения имеют особую актуальность.

Реконструкция, как основное направление строительства, направленное на решение проблем социальных, экологических, экономических и градостроительных ценностей, должна быть целенаправленной и обеспечивать комфортную среду для людей как на местном, так и на глобальном уровне. Целенаправленность принимаемых решений зависит от правильного обеспечения всех этапов жизненного цикла реконструкции зданий и сооружений, начиная от предпроектной и заканчивая сдачей объекта в эксплуатацию. Как показывает практика, именно выполнение строительно-монтажных работ, как этап жизненного цикла реконструкции, в наибольшей мере определяет срок эксплуатации зданий и сооружений. Поэтому при выполнении работ необходимо применять инновационные и энергосберегающие технологии и материалы для восстановления, усиления и замены отдельных элементов конструкции.

Массовая технология - это реновация зданий, основанная на замене оконных и балконных засыпок, технического оборудования, ремонте элементов балконов и установке специальных ограждений, ремонте помещений без переселения жильцов, утеплении фасадных поверхностей, чердаков и подвалов, реставрации. кровля.

Одним из важнейших шагов реконструкции является снижение потерь тепла за счет устранения эффекта вентиляции входов и лестничных клеток за счет установки специальных входных вестибюлей, изоляции наружных поверхностей лестничных панелей, замены дверных панелей на более энергоэффективные панели.

Основная проблема жилых домов с частично выработанным ресурсом - низкая энерго- и ресурсоэффективность, а также экологичность из-за износа элементов здания при эксплуатации без ремонта.

В ходе реконструкции улучшаются эксплуатационные характеристики жилых домов. Важнейшей из этих характеристик является тепловой КПД здания, который определяется среднегодовым расходом топлива на отопление и горячее водоснабжение одного квадратного метра общей площади.

В связи с высокой степенью износа деревянных окон в реконструируемых зданиях необходимо реализовать потенциал энергосбережения (до 30\%) новых энергоэффективных оконных конструкций, которые являются высокорентабельным (более 20\%) техническим решением вместе с утепление наружных стен старых построек. $[4,5]$.

Таким образом, экономия тепловой энергии при реализации энергосберегающих мероприятий может достигать в среднем 59\% для домов первой типовой серии под реконструкцию, в том числе:

- 25\% - за счет повышения теплоизоляции наружных стен и чердаков холодных чердаков;

- $10 \%$ - за счет повышения тепловой защиты окон;

- 6\% - за счет уменьшения избыточного воздухообмена в квартирах;

- 18\% - за счет установки АСУ ТП и установки термостатов на отопительные приборы.

Дополнительно повышенный комфорт жителей обеспечивается возможностью индивидуального регулирования температуры воздуха в квартирах.

Выводы. Реконструкция и модернизация существующего жилого фонда обеспечит уменьшение объемов выбытия жилья из-за морального износа, снижение затрат на потребление и энергопотери, повышение 
безопасности и комфорта жизни, а также качества архитектуры зданий. Реконструкция повысит качество жилья для потребителей на вторичном рынке и ускорит приватизацию, а также будет способствовать прогрессу в реформировании жилищно-коммунального хозяйства, когда более низкие счета за коммунальные услуги компенсируют более высокие цены на энергию.

\section{Литература:}

1. Вольфганг Файст. Основные положения по проектированию пассивных домов. Перевод с немецкого М.: Издательство Ассоциации строительных вузов - 144 с. URL: universalinternetlibrary.ru/book/21373/ogl.shtml (дата обращения: 01.09.2021).

2. Зильберова И.Ю., Петрова Н.Н. Модернизация зданий с целью повышения энергоэффективности, комфорта и безопасности проживания, а также продления срока эксплуатации жилых зданий // ИВД. 2012. №41. URL: http://cyberleninka.ru/article/n/modernizatsiya-zdaniy-s-tselyu-ovysheniyaenergoeffektivnosti-komforta-ibezopasnosti-prozhivaniya-a-takzhe-prodleniya-sroka (дата обращения: 01.09.2021).

3. Самарин О.Д. и др. Оценка энергоэффективности зданий и сравнительная эффективность энергосберегающих мероприятий. // Сб. докл. 9-й конф. РНТОС 25 мая 2004 г.

4. Табунщиков Ю. А. и др. Пути повышения энергоэффективности эксплуатируемых зданий. - АВОК №5/2009.

5. Шеина С.Г., Миненко А.Н. Анализ и расчет «мостиков холода» с целью повышения энергетической эффективности жилых зданий // ИВД. 2012. №4-1. URL: http://cyberleninka.ru/article/n/analiz-i-raschet-mostikovholoda-s-tselyupovysheniya-energeticheskoy-effektivnosti-zhilyh-zdaniy (дата обращения: 01.09.2021).

\section{REFERENCES}

1. Wolfgang Feist. The main provisions for the design of passive houses. Translated from German - Moscow: Publishing House of the Association of Construction Universities - 144 p. URL: universalinternetlibrary.ru/book/21373/ogl.shtml (date of access: 01.09.2021).

2. Zilberova I.Yu., Petrova N.N. Modernization of buildings in order to improve energy efficiency, comfort and safety of living, as well as extending the life of residential buildings. 2012 . №4-1. URL: http://cyberleninka.ru/article/n/modernizatsiya-zdaniy-s-tselyu-ovysheniyaenergoeffektivnosti-komforta-i-bezopasnostiprozhivaniya-a-takzhe-prodleniya-sroka (retrieved 2021-09-01).

3. Samarin O.D. et al. Evaluation of energy efficiency of buildings and comparative efficiency of energy-saving measures. Sat. dokl. 9th Conf. RNDTO May 25, 2004.

4. Tabunshchikov Y. A. et al. Ways to improve the energy efficiency of operated buildings. - AWOC No5/2009.

5. Sheina S.G., Minenko A.N. Analysis and calculation of "cold bridges" in order to increase the energy efficiency of residential buildings. 2012. №4-1. URL: http://cyberleninka.ru/article/n/analiz-i-raschet-mostikov-holoda-stselyupovysheniya-energeticheskoy-effektivnosti-zhilyh-zdaniy (retrieved 2021-09-01).

\section{Информация об авторе}

Яхья Мохаммед Яхья Мохаммед, кандидат технических наук, старший преподаватель кафедры архитектуры и градостроительства, Белгородский государственный технологический университет им. В.Г. Шухова.

Доцент кафедры архитектуры, Курский государственный университет.

Ответственный автор Яхья Мохаммед Яхья Мохаммед

телефон для связи - 8-961-170-96-90

Адрес для пересылки авторского экземпляра (при его заказе)

Яхья М.Я.М.

Россия, 308012, Белгород, ул. Костюкова, д. 46.

Yahya Mohammed Yahya Mohammed1

Yahya Mohammed Yahya Mohammed ${ }^{1}$ - PhD, Senior Lecturer of the Department of Architecture and Urban

Planning, Belgorod State Technological University named after V. G. Shukhov,

Belgorod

$\mathrm{PhD}$, Associate Professor of the Department of Architecture, Kursk State University, Kursk

Information about the author

Yahya Mohammed Yahya Mohammed, PhD, Senior Lecturer, Department of Architecture and Urban Planning, Belgorod State Technological University named after V.G. Shukhov.

Associate Professor of the Department of Architecture, Kursk State University. 